\title{
CONSIDERAÇÕES INICIAIS SOBRE A INTERNET \\ E O SEU USO COMO INSTRUMENTO DE DEFESA DOS \\ DIREITOS HUMANOS, MOBILIZAÇÃO POLÍTICA E SOCIAL
}

\section{Eduardo Akira Azuma}

Bacharel em Direito e Mestrando em Teoria do Estado e do Direito pela Univem de Marília-SP, e membro pesquisador do NEPI (Núcleo de Estudos, de Pesquisas e de Práticas Interativas), filiado ao CNPQ.

e-mail: akira_azuma1@yahoo.com.br

RESUMO: $O$ presente artigo traça algumas considerações iniciais sobre 0 surgimento da Internet, bem como sua utilização na defesa dos Direitos Humanos, nos movimentos sociais e políticos. As primeiras redes de computadores surgiram no final da década de 1960, e, juntamente com a revolução dos microprocessadores, deram início à grande rede das redes, a Internet. Pela sua própria estrutura descentralizada, de características rizomáticas, que permite a emissão e recepção de forma livre de informações, a Internet cresceu exponencialmente sem qualquer instância que dirigisse este processo. Tais características fazem da Internet uma tecnologia que desde a sua formação se assemelha ao projeto da modernidade. Esta nova tecnologia inaugura novas ordens paradigmáticas e novos desafios ao direito. Seu alcance global pode ser utilizado na defesa de direitos humanos e para a mobilização política e social. Alguns exemplos de utilização neste sentido e que foram bem sucedidos são o caso do Chiapas no México e do grandioso protesto contra a OMC em Seattle. A liberdade de expressão, a intimidade e a privacidade, a liberdade de acesso às informações, direitos autorais, entre outras, são questões que costumeiramente enfrentam problemas pelo uso indevido e pela tentativa de controle da Internet. Apesar do uso abusivo, é possível o seu uso na defesa dos novos direitos advindos desta nova tecnologia.

PALAVRAS-CHAVE: Direito; Internet; Direitos humanos; Novos direitos. 


\section{INTRODUÇÃO}

A Internet está cada dia mais presente na vida de todos. Ainda assim, são muitos os excluídos desta nova tecnologia de comunicação.

Mesmo com tamanha exclusão e com as manchetes dos jornais anunciando o caráter cada vez mais comercial da Internet, busco, por meio deste artigo, analisar a estrutura da formação desta rede e como ela pode contribuir para emancipação e defesa dos Direitos Humanos.

Inicialmente busco trazer algumas considerações iniciais sobre o surgimento da Internet, e alguns aspectos culturais do contexto de seu desenvolvimento, utilizando como referencial teórico o sociólogo Manuel Castells.

Pela análise de suas características, e o seu aspecto rizomático, ou seja, uma rede descentralizada, onde cada usuário é fonte emissora e receptora de informações de forma livre, é possível traçar uma semelhança entre a cibercultura e os ideais da modernidade.

Uma utilização neste sentido, permite reduzir de certa maneira o poder da indústria cultural e caminhar para o universal sem totalidade, conforme observa 0 francês Pierre Lévy.

Por fim, o artigo traz alguns exemplos de como estas novas tecnologias da informação transformam os mais diversos setores, inaugurando uma nova ordem paradigmática para a sociedade e novos desafios para o Direito.

Conforme o referencial de Pierre Lévy, parto do pressuposto de que a Internet não traz consigo nem a salvação nem a perdição, é um Pharmakon, ou seja, nem remédio nem veneno, o seu uso é que determinará o futuro desta tecnologia.

\section{CONSIDERAÇÕES INICIAIS SOBRE O SURGIMENTO DA INTERNET.}

A Internet tem as suas origens a partir de 1969, com o desenvolvimento de uma rede de computadores chamada Arpanet, criada por um dos departamentos da Advanced Research Projects Agency (ARPA), que pertencia ao departamento de defesa dos Estados Unidos.

As pesquisas naquele período eram motivadas pelo desejo de superioridade em relação à União Soviética, que havia lançado recentemente o primeiro Sputnik. $O$ 
objetivo do departamento responsável pela criação da Arpanet, definido pelo seu diretor, Joseph Licklider, era o de estimular a pesquisa em computação interativa, utilizando uma revolucionária tecnologia de transmissão de dados por comutação por pacotes, desenvolvida por um centro de pesquisas californiano chamado Rand Corporation (CASTELLS, 2003).

Interessante observar que esta tecnologia foi oferecida ao Departamento de Defesa norte americano como um meio de se criar uma rede de comunicações descentralizada, flexível e que fosse capaz de resistir a ataques nucleares, entretanto, essa não era a finalidade inicial da Arpanet.

Tanto que os primeiros nós ${ }^{1}$ desta rede foram em universidades, visando a troca de informações e o desenvolvimento de pesquisas na área de computação. Mais precisamente, conforme observa Castells (2003), tais nós surgiram em Los Angeles e Santa Bárbara, ambas na Universidade da Califórnia, Universidade de Stanford e Universidade de Utah.

O caminho seguinte foi o de incorporar novas redes à Arpanet, formando uma rede das redes. Aliada à revolução dos microprocessadores, e a outras fontes de rede como os BBS (Bulletin Board System), movimento que brotou no final da década de 70 com a conexão de computadores de uso pessoal, uma grande rede de dimensões globais estava surgindo.

Outro dado importante no processo de formação da Internet é o papel dos chamados programas de fonte aberta. Tal importância reside no fato de que este verdadeiro movimento visava o compartilhamento e o livre acesso de toda a informação relativa a sistemas de software.

Este movimento nos apresenta um pouco do pensamento no qual foi se formando a Internet, e acabou gerando o que se chama hoje de copyleft, ${ }^{2}$ proposta

\footnotetext{
${ }^{1}$ Um conjunto de nós interconectados formam uma rede. A definição de um nó depende de que espécie de rede está se falando. "Concretamente, o que um nó é, depende do tipo de redes concretas de que falamos. São mercados de bolsas de valores e suas centrais de serviços auxiliares avançados na rede dos fluxos financeiros globais. São conselhos nacionais de ministros e comissários europeus da rede política que governa a União Européia. São campos de coca e de papoula, laboratórios clandestinos, pistas de aterrissagem secretas, gangues de ruas e instituições financeiras para lavagem de dinheiro (...)" (CASTELLS, 1999: p.498)

${ }^{2}$ O copyleft foi uma reação proposta por Richard Stallman, programador de Inteligência Artificial do MIT (Massachussets Institute of Technology), em decorrência da decisão da empresa de comunicações AT\&T reivindicar direitos de propriedade sobre o sistema operacional Unix (CASTELLS, 2003). Posteriormente criou também o Free Software Foundation (Fundação para o Software Livre) que é dedicada à eliminação de restrições sobre a cópia, redistribuição, entendimento e modificação de programas de computadores, atuando também no desenvolvimento destes novos softwares.
} 
de Richard Stallman, que tem por objetivo o uso, distribuição e modificação de forma livre de um determinado software.

Essa cultura que permeou o início do desenvolvimento da Internet nos mostra que ela moldou de certa maneira o meio, ou seja, os jovens (note-se a importante participação da Califórnia ${ }^{3}$ ) que contribuíram para o surgimento desta tecnologia primavam pelo desenvolvimento, inovação, cooperação e comunicação de forma livre, muitas vezes se assemelhando aos movimentos de contra-cultura da época.

Essa observação também é feita por Pierre Lévy (1999, p.31) em relação ao desenvolvimento dos computadores pessoais: "Por outro lado, um verdadeiro movimento social nascido na Califórnia na efervescência da "contracultura" apossouse das novas possibilidades técnicas e inventou o computador pessoal".

Com a Internet se tornando um espaço cada vez mais comercial, é interessante essa cultura que a cerca, principalmente a cultura hacker ${ }^{4}$, que demonstra desde o início a emergência de um espaço de interação construído coletivamente, de forma descentralizada e sem qualquer instância que dirigisse ou direcionasse este processo.

As grandes empresas do setor como a Microsoft, dominam a grande rede hoje, mas não se pode dizer que sejam criadoras da tecnologia que deu origem à Internet, muito menos que compartilham do pensamento dos círculos acadêmicos que ajudaram a desenvolver essa rede.

Ao afirmar o primado dos direitos de propriedade (Gates: "Quem pode se permitir fazer um trabalho profissional a troco de nada?"), Gates pôs o ganho de dinheiro antes da inovação tecnológica. Assim, a Microsoft representou a corrente empresarial que se desenvolveu mediante a comercialização do processo de inovação tecnológica em computação, sem compartilhar seus valores fundamentais (CASTELLS, 2003: p. 35).

${ }^{3}$ Deleuze nos revela uma análise no sentido de que a América inverteu as posições, colocando o seu oriente no oeste. O oeste é rizomático, e tudo que aconteceu de importante na América, procede por rizoma: beatnik, underground, subterrâneos, bandos etc. (DELEUZE E GUATTARI, 1995)

${ }^{4} \mathrm{O}$ termo hacker é fonte de muitos mal-entendidos e de várias definições. É salutar mencionarmos que não se trata de irresponsáveis de espírito destrutivo, os que comportam-se de tal forma são os crackers, subcultura do universo hacker. "a cultura hacker, a meu ver, diz respeito ao conjunto de valores e crenças que emergiu das redes de programadores de computador que interagiam on-line em torno de sua colaboração em projetos autonomamente definidos de programação criativa" (LÉVY apud CASTELLS, 2003: p.38) 
Ainda, é possível visualizarmos também a semelhança desta cibercultura ${ }^{5}$ com os ideais lluministas e com o projeto da Modernidade. A confiança na ciência e no desenvolvimento tecnológico como fatores indispensáveis para o desenvolvimento da humanidade fazem parte da cultura das primeiras comunidades de programadores da Internet.

\section{UMA ESTRUTURA DIVERSA DAS MÍDIAS CLÁSSICAS E UM INSTRUMENTO QUE PERMITE A RETOMADA DO PROJETO DE AUTONOMIA DA MODERNIDADE}

Diferente de outras mídias como o rádio e a TV, a Internet se difere por tornar os seus usuários, pólos emissores e receptores de informação. É uma relação de muitos para muitos, ou seja, um sistema opositor do tradicional modelo com uma fonte e vários escoadouros de informação.

Em alguns aspectos o grandioso projeto da Modernidade não obteve sucesso, apenas à guisa de exemplificação, cito o mito da autonomia frente ao universal totalizante, inflexível, inimigo das idiossincrasias, ${ }^{6}$ denunciado pela escola de Frankfurt como uma modernidade obcecada com a ordem, de tendência totalitária e forte caráter standardizador.

Distinções enfáticas, como entre filmes de classe $A$ e $B$, ou entre estórias em revistas a preços diversificados, não são tão fundadas na realidade, quanto, antes, servem para classificar e organizar os consumidores a fim de padronizá-los. Para todos, alguma coisa é prevista a fim de que nenhum possa escapar; as diferenças vêm cunhadas e difundidas artificialmente. $O$ fato de oferecer ao público uma hierarquia de qualidades em série, serve somente à quantificação mais completa. (HORKHEIMER e ADORNO, 1990, p.159)

Esta característica estrutural da Internet de ser descentralizada e com várias fontes produtoras de informação permite (além de uma certa relativização do poder da indústria cultural, como procuro demonstrar posteriormente), novas formas de retomada do ideal iluminista a partir de uma idéia de democracia que vislumbre garantir a autonomia do indivíduo.

${ }^{5} \mathrm{O}$ termo significa "o conjunto de técnicas (materiais e intelectuais), de práticas, de atitudes, de modos de pensamento e de valores que se desenvolvem juntamente com o crescimento do ciberespaço" (LÉVY, 1999, p.17). 
Se a pós-modernidade decreta o fim da era das grandes utopias, a Internet pode ser considerada um meio que retoma tais ideais. Além disso, abrir caminho para possibilidades pós-modernas da Internet é algo dificultoso no sentido de que não há teoria política pós-moderna adequada para ela. (POSTER, 1995).

A própria cibercultura pode ser considerada como movimento que dá continuidade aos ideais iluministas de liberdade, igualdade e fraternidade.

Em contraste com a idéia pós-moderna do declínio das idéias das luzes, defendo que a cibercultura pode ser considerada como herdeira legítima (ainda que longínqua) do projeto progressista dos filósofos do século XVIII. (...)Na era das mídias eletrônicas, a igualdade é realizada enquanto possibilidade para que cada um emita para todos; a liberdade é objetivada por meio de programas de codificação e do acesso trans-fronteiriço a diversas comunidades virtuais; a fraternidade, enfim, transparece na interconexão mundial. (LÉVY, 1999, p. 245)

Insta salientarmos que este retorno aos ideais iluministas não nos remete ao período da modernidade inflexível de universalidade compulsória e totalitária, inimigo da diferença e das idiossincrasias.

A Internet permite o universal sem totalidade. E antes de classificarmos prematuramente esta afirmação como pós-moderna, devemos lembrar que são coisas distintas, "a filosofia pós-moderna confundiu o universal e a totalização" (LÉVY, 1999). Isso significa que pela sua própria estrutura e desenvolvimento (descentralização e desenvolvimento caótico), a relação entre universalidade e totalidade da Internet passa por uma relação inversamente proporcional, ou seja, quanto mais a grande rede se universaliza, menos se torna totalizável.

"Cada conexão suplementar acrescenta ainda mais heterogeneidade, novas fontes de informação, novas linhas de fuga, a tal ponto que o sentido global encontra-se cada vez menos perceptível, cada vez mais difícil de circunscrever, de fechar, de dominar" (LÉVY, 1999, p. 120).

Conforme visto alhures, diferente de outras mídias, a Internet possui a qualidade de fazer com que os seus usuários sejam emissores e receptores de informação de forma livre, sem qualquer hierarquia ou órgão censor e controlador.

6 Nas palavras de Zygmunt Bauman, esta modernidade é diferente da modernidade de hoje por "parecer pesada (contra a leve modernidade contemporênea); melhor ainda, sólida (e não fluida, líquida ou liquefeita); condensada (contra difusa ou capilar); e, finalmente, sistêmica (por oposição a em forma de rede)." (BAUMAN, 2001, p.33) 
Esta característica nos permite pensar no caráter rizomático ${ }^{7}$ da Internet, possuindo grande importância no momento em que passamos a analisar os seus efeitos.

Se retomarmos a idéia do projeto de autonomia cultural da modernidade, que visava o livre acesso à produção cultural sem qualquer espécie de tutela, é fácil constatar que a Internet promove a relativização do poder da indústria cultural, posto que ela elimina editores, produtores ou qualquer espécie de intermediário que possa interferir na livre produção de cultura e de mensagem.

Tome-se o e-mail o símbolo virtual, e será fácil concluir como a escola de Frankfurt não teria meios de decodificá-lo (tal como fizeram analisando a subsunção da cultura à economia, com a cultura sendo transformada em prol da indústria cultural e resultando na massificação produtiva dos próprios signos, significados e sujeitos culturais) (MARTINEZ, 2003, p.147).

Além disso, a Internet também facilita o acesso a tais produções na medida em que a fonte onde elas estão disponíveis não é única. Assim, permite-se a diversidade e distancia-se da standardização dos bens culturais pela livre escolha dos seus usuários.

Outro aspecto que merece ser analisado é a contribuição da Internet para um projeto que garanta a autonomia segundo um modelo democrático. Neste sentido, ela pode atuar num projeto de ordem internacional democrática e também na democracia dentro dos Estados nacionais.

Insta salientarmos que, apesar de ser um meio de comunicação, a proposta de utilizar a grande rede como instrumento democrático e de defesa dos Direitos Humanos tem em vista a possibilidade de participação e avaliação contínua nas decisões políticas por parte dos cidadãos, além de ser um instrumento de grande alcance na fiscalização e denúncia de violação aos Direitos Humanos.

No caso da participação política, saliento que não há qualquer semelhança entre essa idéia desenvolvida para a Internet e a política midiática baseada no "tríptico infernal televisão/pesquisas/eleições", o que se busca é o debate coletivo e interativo para o refinamento de opiniões e o enriquecimento das argumentações. (LÉVY, 1999).

\footnotetext{
${ }^{7}$ Nas palavras de Deleuze, "o rizoma conecta um ponto qualquer com outro ponto qualquer e cada um de seus traços não remete necessariamente traços de mesma natureza; (...) o rizoma é um sistema a-centrado não hierárquico e não significante, sem General, sem memória organizadora ou autômato geral, unicamente definido como uma circulação de estados" (DELEUZE e GUATTARI, 1995, p.32-33)
} 
Como instrumento, a Internet proporciona muitas facilidades para a participação e ação coletiva. A barreira da técnica é cada vez menor, haja vista que as interfaces estão se tornando mais amigáveis.

Outras facilidades podem ser apontadas, como a redução do custo institucional e organizacional para a ação de organizações não-governamentais por exemplo. Isso facilita a divulgação e coordenação entre os participantes. Reduz também os custos individuais na medida em que diminui a necessidade dos encontros face-à-face. A criação de comunidades virtuais permite o surgimento de espaços temáticos cuja convergência de idéias formam identidades coletivas. (SCHMIDTKE apud EISENBERG)

$\mathrm{Na}$ construção de uma ordem democrática internacional, as novas tecnologias de comunicação podem contribuir na medida em que aumentam a comunicação e o contato com culturas diversas, e como aponta Rouanet (ROUANET, 2004) podem relativizar os reflexos nacionalistas e combater a xenofobia. Deste modo, as novas tecnologias da informação estariam contribuindo para a conciliação da igualdade com o respeito pela diversidade.

Fora do plano internacional, existem inúmeros movimentos que se utilizam da Internet e suas facilidades para a participação nas decisões locais, ou seja, restritas ao âmbito das cidades. Estes mecanismos de democracia eletrônica permitem que os cidadãos participem da formulação, execução e avaliação das políticas públicas.

O projeto mais importante deste gênero é o Péricles da cidade de Atenas, (...) O projeto visa criar mecanismos formais de participação e deliberação dos cidadãos nos projetos legislativos da cidade. Esta democracia eletrônica funciona com três mecanismos: a) Através de moções publicadas na rede, e da coleta de um número mínimo de assinaturas dos cidadãos, projetos de lei são obrigatoriamente introduzidos para votação na pauta do legislativo municipal, conferindo assim iniciativa legislativa aos cidadãos; b) através de votações eletrônicas, projetos votados no legislativo são submetidos a um referendo eletrônico, que pode ter poder consultivo ou deliberativo; c) através de votações eletrônicas, decisões governamentais passadas podem ser anuladas ou modificadas. (EISENBERG, p.15)

Projetos como este fazem surgir inúmeras questões, por exemplo, para ser realmente democrático todos devem ter acesso à tecnologia. No caso acima, a solução foi a instalação de terminais públicos de acesso para a população carente. 


\section{NOVAS POSSIBILIDADES, NOVOS DIREITOS}

As novas tecnologias de comunicação estão revolucionando vários setores da sociedade, inaugurando uma nova geração de direitos e uma nova ordem paradigmática para a sociedade.

A passagem do século $X X$ para o novo milênio reflete uma transição paradigmática da sociedade industrial para sociedade da era virtual. É extraordinário o impacto do desenvolvimento da cibernética, das redes de computadores, do comércio eletrônico, das possibilidades da inteligência artificial e da vertiginosa difusão da Internet sobre o campo do direito, sobre a sociedade mundial e sobre os bens culturais do potencial massificador do espaço digital. (WOLKMER, 2001, p.12)

A partir do surgimento e da proliferação deste tipo de tecnologia, direitos humanos fundamentais como a intimidade e a privacidade, acesso à informação, direitos de autor, liberdade de expressão dentre outros, passam a ter novos contornos e passam a ser novos desafios a serem enfrentados pelo direito.

No campo da privacidade e da intimidade por exemplo, o uso destas novas tecnologias de forma abusiva vem se tornando rotineira, podendo haver um retorno a antigos temores e pesadelos orwellianos que assombravam a sociedade a décadas atrás.

Ainda que o uso demasiado comercial ou de forma abusiva aos direitos do homem esteja sendo cada vez mais praticado, existem outros usos e outras transformações em setores mais diversos.

Para citar alguns exemplos desta transformação, no campo pedagógico abrem-se novas formas de ensino à distância, sem a passividade dos modelos anteriores, ou seja, com a possibilidade de interação entre aluno e professor.

No campo das artes temos o surgimento de novas formas artísticas que tornam a postura do observador mais interativa do que contemplativa. ${ }^{8} \mathrm{~A}$ música e a literatura também adquirem novos contornos com as redes como a Internet. No caso da música (além dos já conhecidos problemas com os direitos autorais, pirataria etc.), um novo modelo baseado na interligação entre os músicos e as suas criações que alimentam um banco de amostras musicais (samples), geram uma espécie de

\footnotetext{
8 Pierre Lévy também cita duas manifestações internacionais de grande repercussão. a "Ars Electronica" em Linz, na Áustria e a "ISEA - International Symposium of Electronic Arts" organizado todos os anos em uma cidade diferente pela International Society for Electronic Arts. (LÉVY, 1999)
} 
bricolagem musical. Além disso, o acesso a novos trabalhos e a emergência de novos talentos também é facilitado pelos novos palcos virtuais.

A facilidade e o custo de se publicar algo na Internet propicia um estímulo para os novos escritores, por conseqüência, têm-se também acesso a um número maior e mais diversificado de textos. Claro que isso não implica necessariamente em qualidade, mas, por outro lado, fica mais fácil o acesso à literatura underground, que não se submete a nenhuma exigência comercial por exemplo.

Mas é no campo das manifestações, mobilizações e movimentos sociais e políticos que a Internet tem um destaque importante. $O$ alcance global da grande rede permite uma maior mobilização e um maior recrutamento, denunciando as causas em escala planetária.

Dentre os vários movimentos que se utilizam da Internet como forma de ação global e para a sua própria coordenação, os mais importantes são: movimentos para defesa dos Direitos Humanos, pelos direitos das mulheres, pelo trabalho, ambientalista, religioso e pela paz (COHEN e RAI apud CASTELLS, 2003).

Um exemplo bastante citado na literatura especializada é o caso de Chiapas, no México. Surgido em 1994, os rebeldes zapatistas que atendem pelo nome de Exército Zapatista de Libertação Nacional, tinham como principal objetivo a defesa do índios mexicanos daquela região.

Este movimento se utilizou da Internet para sensibilizar a opinião pública mundial. Dotados de uma grande capacidade de comunicação (eram capazes por exemplo de traduzir uma mensagem para mais de 50 idiomas em 24 horas), por meio de mensagens eletrônicas, eles buscaram o apoio de pessoas e grupos fora do país, além de divulgar a sua causa para o mundo. ${ }^{9}$

No campo da liberdade de expressão também se encontram diversos obstáculos no mundo todo, um exemplo de mobilização pela internet que contribuiu para a efetivação deste direito é o caso ocorrido em 1996 na cidade de Belgrado. A Rádio B92, conhecida como uma estação defensora da democracia, foi alvo de forte censura, culminando com seu fechamento por ordem de Slobodan Milosevic. Todavia, a rádio continuou a transmitir a sua programação via Internet, e desta vez

${ }^{9}$ Tal estratégia de divulgação alcançou as mais diversas pessoas, de intelectuais como o lingüista Noam Chomsky, Alain Touraine e José Saramago até o som politizado de bandas como Rage Against The Machine, Manu Chao, Mundo Livre s/a, O Rappa, Chico Science \& Nação Zumbi etc. 
para todo o globo, surgindo assim apoio de diversos cantos do mundo e uma pressão internacional que forçou Milosevic a retroceder na sua decisão de fechar tal rádio (MITCHELL, 2002).

A questão da liberdade de expressão e da tentativa de controle da rede por parte de governos, como por exemplo a tentativa do governo norte-americano pelo Communications Decency Act (que foi declarado inconstitucional em 1996 em razão da primeira emenda norte-americana garantir a livre expressão), nos mostra a problemática da efetivação deste direito. ${ }^{10}$

Entretanto, principalmente após os atentados de 11 de setembro, o governo norte-americano continua cometendo vários abusos no tocante às liberdade individuais, principalmente por meio das novas tecnologias da informação.

Em contra-partida, os mais heterogêneos grupos com interesses em comum conseguem se mobilizar para uma causa comum também por meio da Internet.

Um outro exemplo considerado paradigmático foram os protestos contra a Organização Mundial do Comércio em Seattle, em dezembro de 1999. Isso porque reuniu grupos com interesses e valores diferentes, de ecopacifistas a operários americanos, mas todos contra uma organização que impunha a "globalização sem representação" (CASTELLS, 2003).

Com a atual onda de monstros tecnológicos criados pela mídia e outros de real existência, existem inúmeras organizações não governamentais e movimentos em defesa dos direitos humanos que se utilizam com sucesso da Internet. Infelizmente a cultura do medo é espalhada de maneira sensacionalista e muitas vezes tais iniciativas não têm o devido destaque da imprensa tradicional, mas isso não impede que obtenham sucesso nas suas ações e que possam servir de exemplo e de instrumento dos países e das comunidades periféricas.

\section{CONCLUSÃO}

Desde o seu surgimento, vemos que a cultura em torno do desenvolvimento da Internet priorizava a construção e a liberdade de acesso à estrutura da 
programação dos softwares, se assemelhando muitas vezes aos movimentos de contra-cultura da década de 70.

Ainda que hoje a Internet esteja cada vez mais na área comercial, ou sendo utilizada como redes controlativas e de vigilância, vemos alguns elementos de suas própria estrutura que permitem uma utilização em favor da defesa de interesses de uma determinada comunidade ou grupo.

O fato desta intrincada rede de comunicações ser descentralizada e permitir que os seus usuários sejam emissores e receptores de informação, torna um projeto de emancipação do homem e da defesa dos seus direitos algo não tão distante, principalmente quando tomamos como referência as mídias tradicionais.

Lembro que muitas dificuldades ainda devem ser enfrentadas, como a questão da exclusão digital, da capacitação técnica e das tentativas de cerceamento em relação à liberdade de acesso e de expressão das informações.

Mas o fato é que, em alguns casos o uso da Internet como instrumento de defesa de Direitos Humanos e mobilização política e social foi muito bem sucedida. Existem vários outros exemplos que poderiam ser citados, mas o objetivo principal foi o de chamar a atenção para uma utilização desta tecnologia em defesa do Direito e em favor do homem.

\section{REFERÊNCIAS BIBLIOGRÁFICAS}

BAUMAN, Zygmunt. Modernidade Líquida. Trad. Plínio Dentzien. Rio de Janeiro: Jorge Zahar, 2001.

CASTELLS, M. A sociedade em rede. São Paulo: Paz e Terra, 1999. v. 1.

CASTELLS, M. A galáxia da Internet - Reflexões sobre a Internet, os negócios e a sociedade. Trad. de Maria Luiza X de A. Borges. Rio de Janeiro: Jorge Zahar Editor, 2003.

DELEUZE, Gilles e GUATTARI, Félix. Mil Platôs - Capitalismo e Esquizofrenia. Trad. de Aurélio Guerra Neto e Célia Pinto Costa. Rio de Janeiro: Ed.34, 1995, v.I.

EISENBERG, José. Internet popular e Democracia nas Cidades. disponível em: www.rits.org.br/ acervo-d/democraciaeletronica.pdf acesso em: 15.abril.2005.

\footnotetext{
${ }^{10}$ No dia 12 de junho de 1996, o tribunal federal dos Estados Unidos declarou a inconstitucionalidade do Communications Decency Act afirmando: "Assim como a força da Internet é o caos, assim a força da liberdade depende do caos e da cacofonia da expressão livre que a primeira emenda protege" (CASTELLS, 2003 , p. 140). Entretanto, principalmente após os atentados de 11 de setembro, o governo norte-americano continua cometendo vários abusos no tocante às liberdade individuais, principalmente
} 
HORKHEIMER, Max e ADORNO, Theodor. A indústria cultural. In: Teoria da Comunicação de Massa. org. Luiz Costa Lima. Rio de Janeiro: Ed. Paz e Terra, 1990.

LÉVY, Pierre. Cibercultura. tradução de Carlos Irineu da Costa. São Paulo: Ed.34, 1999.

LÉVY, Pierre. A inteligência Coletiva. tradução de Luiz Paulo Rouanet. São Paulo: Ed. Loyola, 1998.

MARTINEZ, Vinício C. Rede Política e Indústria Imaterial in Trabalho, Economia e Tecnologia Novas perspectivas para a sociedade global. org. Jorge Alberto Machado. São Paulo: Tendenz; Bauru: Praxis, 2003.

MITCHELL, William J. E-Topia - A Vida Urbana - mas não como a conhecemos. Tradução de Ana Carmen Martins Guimarães. São Paulo: Ed. Senac, 2002.

POSTER, Mark. CyberDemocracy: Internet and the Public Sphere. disponível em: www.forumglobal.de/soc/bibliot/p/cyberdemocracy_poster.htm acesso em 15.abril.2005.

ROUANET, Sérgio Paulo. Democracia Mundial. In: NOVAES, Adauto (Org.). O Avesso da Liberdade. São Paulo: Companhia das Letras, 2003. 